\title{
Article
}

\section{Does the Construction and Operation of High-Speed Rail Improve Urban Land Use Efficiency? Evidence from China}

\author{
Xinhai Lu ${ }^{1,2}$, Yifeng Tang ${ }^{1, *}$ and Shangan $\mathrm{Ke}^{2}$ \\ 1 College of Public Administration, Huazhong University of Science and Technology, Wuhan 430074, China; \\ luxinhai@hust.edu.cn \\ 2 College of Public Administration, Central China Normal University, Wuhan 430079, China; \\ keshangan@ccnu.edu.cn \\ * Correspondence: d201881103@hust.edu.cn
}

Citation: Lu, X.; Tang, Y.; Ke, S. Does the Construction and Operation of High-Speed Rail Improve Urban Land Use Efficiency? Evidence from China. Land 2021, 10, 303. https:// doi.org/10.3390/land10030303

Academic Editor: Piyush Tiwari

Received: 25 February 2021

Accepted: 15 March 2021

Published: 16 March 2021

Publisher's Note: MDPI stays neutral with regard to jurisdictional claims in published maps and institutional affiliations.

Copyright: (c) 2021 by the authors. Licensee MDPI, Basel, Switzerland. This article is an open access article distributed under the terms and conditions of the Creative Commons Attribution (CC BY) license (https:/ / creativecommons.org/licenses/by/ $4.0 /)$.

\begin{abstract}
The construction and operation of high-speed rail (HSR) has become an important policy for China to achieve efficiency and fairness and promote high-quality economic growth. HSR promotes the flow of production factors such as labor and capital and affects economic growth, and may further affect urban land use efficiency (ULUE). To explore the impact of HSR on ULUE, this paper uses panel data of 284 cities in China from 2005 to 2018, and constructs Propensity Score Matching-Differences in Differences model to evaluate the effect of HSR on ULUE. The result of entire China demonstrates that the HSR could significantly improves the ULUE. Meanwhile, this paper also considers the heterogeneity of results caused by geographic location, urban levels and scales. It demonstrates that the HSR has a significantly positive effect on ULUE of Eastern, Central China, and large-sized cities. However, in Western China, in medium-sized, and small-sized cities, the impact of HSR on ULUE is not significant. This paper concludes that construction and operation of HSR should be linked to urban development planning and land use planning. Meanwhile, the cities with different geographical locations and scales should take advantage of HSR to improve ULUE and promote urban coordinated development.
\end{abstract}

Keywords: high-speed rail; urban land use efficiency; propensity score matching-differences in differences; regional heterogeneity; China

\section{Introduction}

Urban land use efficiency (ULUE) reflects the urban economic output on urban land [1-3]. With the rapid development of China's economy and the acceleration of urbanization, China's urban land resources are becoming increasingly tight. Scholars proposed that improving ULUE has become an effective way to alleviate the contradiction between urban economic growth and the shortage of urban land resources [4,5]. The construction and operation of high-speed rail (HSR) is regarded as an important engine for China's economic growth, and it is also a driving force for China to implement high-quality urban development strategies and promote coordinated urban development in the new era [6]. Moreover, the construction and operation of HSR promotes regional production factors flow and produces re-allocation effects, and causes urban land use structure transition. Therefore, HSR may become one of the important factors affecting ULUE.

The previous studies on ULUE mainly include the following aspects: (1) Constructing index system and quantify ULUE. Some scholars use the economic density of urban space to quantity the ULUE [1-3]. Others pointed out that ULUE is the input and output efficiency of various production factors, including land factors. They used the Stochastic Production Frontier Approach [7,8] and Data envelopment analysis [9-11] to quantity the ULUE. Data envelopment analysis is one of the mainstream methods for quantitatively measuring ULUE. However, the data envelopment analysis method ignores the negative environmental externalities generated in the process of urban land use, and it does not 
consider the slack problem of input-output variables. The non-radial and non-angle Slackbased measure model constructed by Tone et al. [12] effectively solves these problems. On this basis, scholars constructed an urban land use efficiency index system that considered both the expected output and other undesired output of urban land use, and they used the Slack-based measure model to evaluate the ULUE [13-15]. (2) Analysis of driving mechanism and influencing factors of ULUE. Previous studies have explored the effect of economic development [16], government policy [17,18], industrial development [19,20], transportation infrastructure construction $[21,22]$ et al. on ULUE. These studies provide a reference for government to formulate policies to improve ULUE.

Since 1 October 1964, the first HSR operated between Tokyo and Osaka in Japan, the construction and operation of HSR has been rapidly expanded within the globe [23]. Due to the fact that construction and operation of HSR improves urban accessibility, promotes regional factor flow and regional integrated development, some scholars proposed that HSR has a positive impact on urban economic development through agglomeration effects [24-26]. However, the construction and operation of HSR also aggravate regional economic polarization by strengthening the central position of large-sized cities in regional economic development. Therefore, small- and medium-sized cities in the regional economy may be marginalized [27-30].

Meanwhile, existing studies have demonstrated that the HSR has promoted land use structure change, and significantly expanded the scope of urban space and increased land value. For example, Chen et al. [31] evaluated the impact of HSR on urban land use structure changes; their research indicated that the operation of HSR reduces the supply of residential and industrial land, but has a positive impact on commercial land and transportation and logistics land. Zhang et al. [32] proposed that the increase in the frequency of high-speed trains promotes the development of local road networks and promotes the centralized expansion of cities. Huang et al. [33] pointed out that, compared with Not-HSR cities, the land value of HSR cities has increased significantly. In the field of ULUE, scholars have found that the construction of highways and other transportation infrastructures has changed the spatial pattern of ULUE through factor agglomeration and spatial spillover effects [21,22]. However, there have few studies about the effect of HSR on ULUE. Especially for China, by the end of 2019, the operating mileage of HSR reached 35,000 km, China has the most modern and developed HSR network in the world [34]. Therefore, exploring the impact of HSR on ULUE is of great significance for evaluating China's HSR development performance, and also could provide policy reference for improving the ULUE and the ability of urban high-quality development.

Based on the above analysis, this paper uses 284 prefecture-level cities in China from 2005 to 2018 as research sample, and constructs Propensity Score Matching-Differences in Differences model to evaluate the effect of HSR on ULUE. Meanwhile, this paper also analyzes the heterogeneity of impact effects among cities of different geographic locations and scales.

\section{Mechanism}

ULUE could be defined as the economic density of urban space, which is calculated by economic output on the urban built-up area [16,35]. Undoubtedly, the optimal allocation of production factors such as labor, capital, and land elements could directly affect urban economic output and ULUE [2,3]. In this paper, the impact mechanism of high-speed rail on urban land use efficiency is summarized as the following two aspects:

Firstly, HSR affects ULUE by directly promoting the flow of production factors and affecting regional economic activities. The HSR is an important carrier of mobile production factors such as labor and capital. Compared with other modes of transportation, the highspeed and high-frequency departure method of HSR have caused the gradual integration of small- and medium-sized cities less than one hour away from large-sized cities into metropolitan areas [36,37]. For example, in the Yangtze River Delta of China, Nanjing, Jiaxing, Hangzhou, Suzhou, Wuxi, Changzhou, and Zhenjiang can reach the regional center 
Shanghai by HSR within one hour (data from https://www.12306.cn/index/, accessed on 10 December 2020). The resident's lifestyles in the regions has been changed dramatically, because HSR creates off-site employment conditions for some highly skilled laborers living in surrounding cities who cannot afford the high housing prices in the central urban $[38,39]$. Meanwhile, the construction and operation of HSR promote capital flows and enables cities to obtain capital input. Lin et al. [39] demonstrated that after the operation of HSR, investment between cities could increase by $38 \%$. The research conducted by Duan [40] also indicated that the construction and operation of HSR reduces commuting time between cities and leads to an increase of 0.0222 transactions in venture capital between cities each year. The increase in capital input could promote the upgrading of urban industrial structure and further gather more advanced production factors, which could affect the ULUE $[10,41]$. These changes mean that the high-speed railway strengthens the economic connection between cities, and the regional socioeconomic development pattern has been reshaped. As the major space of urban economic activities, the efficiency of urban land may also change with the transition of regional economic pattern brought by HSR.

Second, the construction and operation of HSR affect ULUE by leading to land use structure transition. The HSR stations in China are generally located in suburbs or villages. Due to the fact that land transfer can increase the economic performance of local governments, China local governments tend to adopt "HSR-new district planning" near HSR stations to encourage land development. Specifically, the government promotes the use and development of land around HSR stations by formulating reasonable urban land use planning. For example, the "Zhengdong New District" near Zhengzhou East Railway Station, and the "Wuguang New City" near Changsha South Railway Station are now prosperous metropolitan areas. However, the land use of these places used to be mainly agricultural land and even unused land ten years ago. With the construction and operation of HSR, the land use near the station is oriented for HSR and the area of residential land, commercial land, transportation and storage land has been expanded [31,42]. With the transition of land use structure, urban land use efficiency may also change.

Based on the above analysis, this paper proposes that the construction and operation of HSR may have an impact on ULUE, and this paper will be further explored below. The impact mechanism analysis is shown in Figure 1.

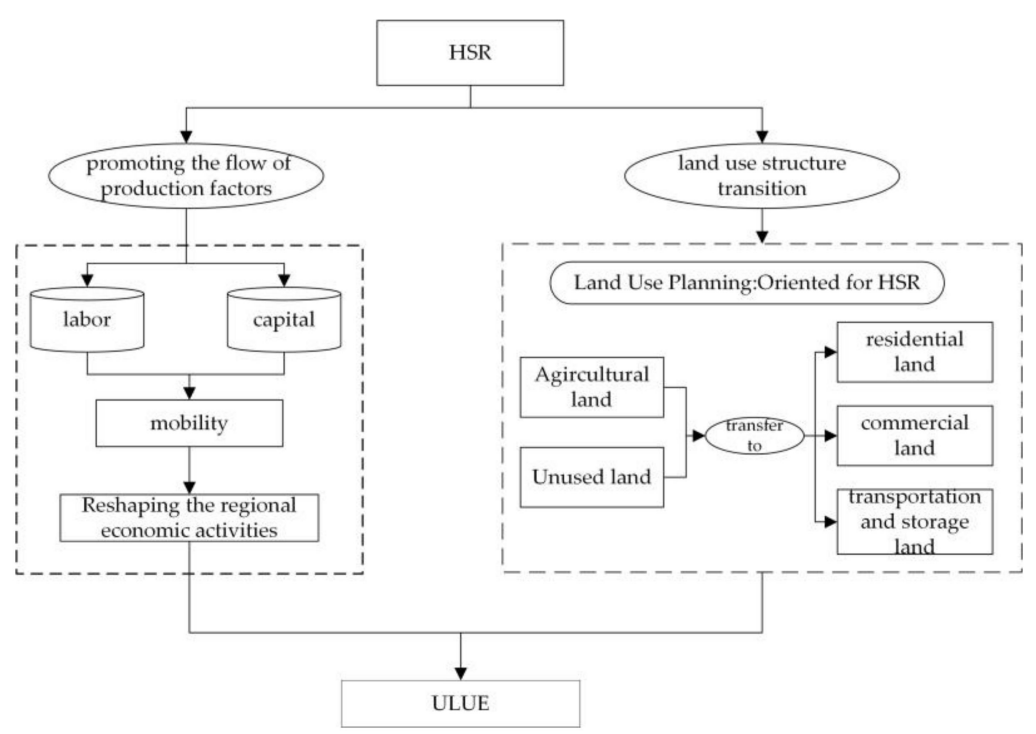

Figure 1. Impact mechanism framework of HSR on ULUE.

\section{The Construction and Operation Condition of HSR in China}

On 1 August 2008, the Beijing-Tianjin intercity high-speed railway was operated. This line is recognized as the first HSR in China and its maximum operating speed can 
reach $350 \mathrm{~km} / \mathrm{h}[43,44]$. The Beijing-Shanghai high-speed railway started operation on 30 June 2011, which connects important cities in China such as Beijing, Tianjin, Jinan, Xuzhou, Nanjing, Wuxi, Suzhou and Shanghai. The Beijing-Guangzhou high-speed railway, which began operating on 26 December 2012, is considered to be the longest operating HSR in the world. The line also connects important Chinese cities such as Beijing, Shijiazhuang, Zhengzhou, Wuhan, Changsha and Guangzhou. Although the construction and operation of China's HSR shows a rapid development trend, to ensure safety and reduce operating costs, China National Railway Corporation implemented railway speed reduction on 1 July 2011. The maximum operating speed of HSR dropped from $350 \mathrm{~km} / \mathrm{h}$ to $300 \mathrm{~km} / \mathrm{h}$. Other railways with a maximum operating speed of $250 \mathrm{~km} / \mathrm{h}$ and $200 \mathrm{~km} / \mathrm{h}$ have also implemented a speed reduction policy. In fact, this policy cannot stop the construction and operation process of HSR in China. By the end of 2018, the operating mileage of China's HSR reached more than $29,000 \mathrm{~km}$ [34]. China has the most modern railway network and the most developed HSR network in the world.

In the "Code for Design of High-speed Railways" promulgated by China National Railway Corporation, HSR is defined as a passenger-dedicated line with a standard gauge for high-speed trains and the designed speed of $250 \mathrm{~km} / \mathrm{h}$ to $350 \mathrm{~km} / \mathrm{h}$. However, other railways with a designed speed of $200 \mathrm{~km} / \mathrm{h}$ also have EMU trains running. Hence, the National Development and Reform Commission of China regards some $200 \mathrm{~km} / \mathrm{h}$ railways as high-speed railways in China's "Medium and Long-term Railway Network Planning".

Combining the data continuity and the adjustment of the administrative divisions of Chinese cities, this paper selected 284 prefecture-level cities from the China City Statistical Yearbook. According to China's railway timetable, 199 cities in China have high-speed rail stations in 2018, we call them HSR cities. For the cities that do not have HSR, we call them Not-HSR cities. Figure 2 shows the distribution map of China's HSR (operating speeds of $200 \mathrm{~km} / \mathrm{h}$ and above). The HSR data come from OpenStreet (https:/ / download.geofabrik. de/asia/china.html\#, accessed on 10 December 2020).

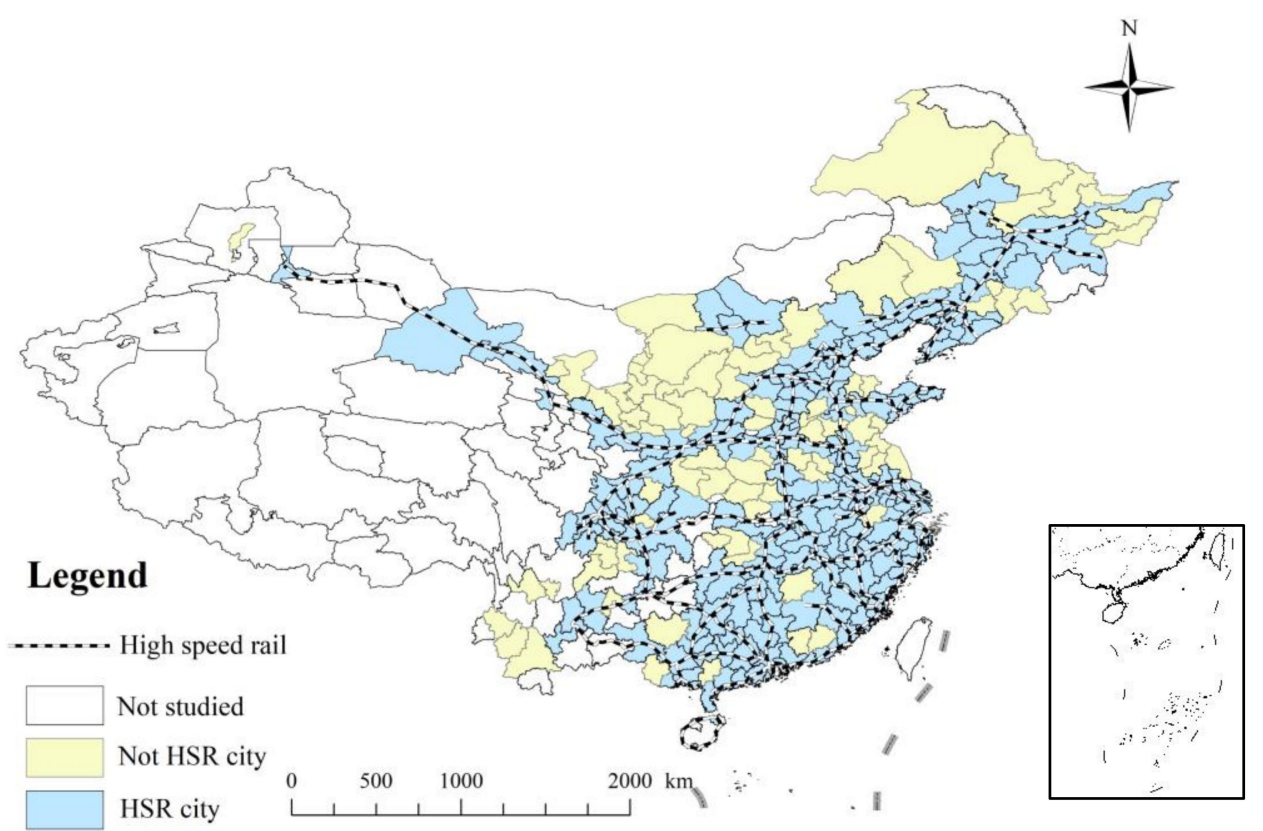

Figure 2. Construction and operation of China's major HSR in 2018. 


\section{Methodology and Data Sources}

\subsection{Differences in Differences (DID)}

Scientific evaluation of the impact of HSR on ULUE was the main purpose of this paper. The Differences in Differences method can effectively separate the "time effect" caused by the natural growth and the "policy processing effect" caused by the construction and operation of HSR. Meanwhile, DID can effectively avoid the endogenous problems of policy variables, and can obtain an unbiased estimate of the policy results [45]. Therefore, scholars constructed the DID model to reflect the influence of HSR by comparing the performance differences between the treated group (HSR city) and the untreated group (Not-HSR city) $[44,46,47]$. This paper constructs the following DID method to evaluate the effect of HSR on ULUE:

$$
\text { ULUE }_{i t}=\alpha+\beta_{1} \text { period }_{i t}+\beta_{2} \text { treated }_{i t}+\beta_{3}\left(\text { period } \times \text { treated }_{i t}+\mu_{i}+\varepsilon_{i t}\right.
$$

In Equation (1), the $U L U E_{i t}$ denotes urban land use efficiency.

period $_{i t}$ denotes time dummy variables. Combining with the study of Shaw [44], the construction and operation of China's HSR can be divided into four stages. First Stage: Before August 2008, there was no HSR construction and operation service in China. Second Stage: From August 2008 to June 2011, China had constructed and operated five main HSR, including Beijing to Tianjin, Wuhan to Guangzhou, Beijing to Shanghai, Zhengzhou to $\mathrm{Xi}^{\prime}$ an and Ningbo to Fuzhou. Third Stage: To ensure safety and reduce operating costs, China National Railway Corporation implemented railway speed reductions on 1 July 2011. Although the reduction policy of HSR has brought many adverse effects on China's economic development, China's high-speed rail construction has increased rapidly from $9790 \mathrm{~km}$ in 2001 to 29,000 km in 2018; more Chinese cities have HSR stations and enjoy the benefits of HSR. Therefore, basing on the research of Dong [6], this paper selected 2011 as the implementation date. After the implementation date of HSR operation, period $=1$. Otherwise, period $=0$.

treated $_{i t}$ denotes individual dummy variables. For the city with HSR operation, treated $=1$, and these cities belong to the treated group. While for the city with no HSR operation, treated $=0$, and these cities belong to the untreated group. In this paper, according to the research of Dong [6], we took the cities that have HSR before 2011 (including 2011) as the treated group. The untreated group includes Not-HSR cities after 2011, and the cities that have HSR after 2011 were removed from the untreated group. Finally, the number of cities in the treated group is 65, and the number of cities in the untreated group is 85 .

$(\text { period } \times \text { treated })_{i t}$ denotes the urban dummy variable after HSR operation. $\alpha, \beta$ denotes the coefficient. $\mu$ represents individual fixed effects. $\varepsilon$ denotes residual. $i$ denotes city. $t$ denotes year.

\subsection{Propensity Score Matching (PSM)}

Propensity Score Matching regards the construction and operation of HSR in each city as an exogenous decision-making process, and uses the later explanatory variables and covariates reflecting other development characteristics of each city as explanatory variables. It estimates the probability of HSR in a city through logit regression model. This probability is the Propensity Score of each city's tendency to have HSR. The basic forum of PSM is as follows:

$$
P_{i}(X)=\operatorname{Pr}\left(\text { treated }_{i t}=1 \mid X_{i}\right)=F\left[h\left(X_{i}\right)\right]
$$

In Equation (2), treated $_{i t}$ denotes the dummy of the treated group. $X_{i}$ represents the development characteristics of each city covariates. $h(\bullet)$ denotes linear function. $F(\bullet)$ denotes logit function. The matching criteria are: there is no significant difference in Propensity Score between the treated group and the untreated group. 


\subsection{PSM-DID}

If the DID method cannot meet the following two assumptions, the results may be biased: On the one hand, before the operation of HSR, the treated group and the untreated group should have similar time change trend. On the other hand, the construction and operation of HSR is exogenous for each city, and whether HSR is constructed and operated in each city has nothing to do with other characteristic variables such as the economic development level. Although the DID may not satisfy these assumptions, Heckman [48] and Rosenbaum [49] use the Propensity Score Matching method to eliminate the bias in the process of sample selection.

Based on the above analysis, this paper finally adopts the Propensity Score Matching method combined with the double difference method (Propensity Score MatchingDifferences in Differences (PSM-DID)) to explore the effect of HSR on ULUE. The basic form of PSM-DID is as follows:

$$
U_{L U E_{i t}}^{\text {PSM }}=\alpha+\beta_{1} \text { period }_{i t}+\beta_{2} \text { treated }_{i t}+\beta_{3}\left(\text { period } \times \text { treated }_{i t}+\beta_{4} X_{i t}+\mu_{i}+\varepsilon_{i t}\right.
$$

In Equation (3), $X_{i t}$ is a set of control variables that affect the ULUE and also a covariate that affects whether the city has HSR. The remaining variables are consistent with the above.

\subsection{Variables and Data Source}

Explained variable: Urban land use efficiency (ULUE). ULUE could be defined as the economic density of urban space, which is calculated by the added value of the secondary and tertiary industries by the urban built-up area [16,35]. Capital, labor and other production factors are invested in a certain area of urban land and generated economic output. The added value of the secondary and tertiary industries per unit of built-up area is the mainstream index to represent the ULUE $[2,3,50,51]$. Hence, this paper calculated the ULUE by the following formula:

$$
U L U E_{i t}=\frac{N A O_{i t}}{B U A_{i t}}
$$

In Equation (4), $N A O_{i t}$ denotes the added value of the secondary and tertiary industries to represent it. $B U A_{i t}$ denotes the built-up area.

Key explanatory variable: This paper selects the time dummy variable period $_{i t}$, individual dummy variable treated $_{i t}$ and their interaction terms (period $\times$ treated $_{i t}$ as explanatory variables. Specifically, the time dummy variable reflects the ULUE-change difference before or after the operation of HSR. The individual dummy variable reflects the ULUE-change difference of HSR city and Not-HSR city. (period $\times$ treated) ${ }_{i t}$ is the key explanatory variable of this paper, which represents the impact of HSR on ULUE. Their specific values have been explained in Equation (1).

Control variables: This paper also selects a set of control variables that may affect ULUE over time. (1) Economic. The higher the level of economic development, the more high-quality production factors can be attracted to cities, which may improve the ULUE. Drawing on the existing research [2,52], this paper uses per capita GDP to measure the level of urban economic development. (2) Capital. Capital input could promote urban infrastructure construction and sustainable urban development, and generate economic agglomeration effects. Therefore, the capital has an effect on ULUE [10,42]. Basing on the previous studies [10], the total investment of fixed assets is selected to quantify urban capital input. (3) Labor. The increase in the number of urban labor forces promotes the formation of better job matching in cities and realizes knowledge spillover through the exchange of human capital. Thereby, the labor input has a significant impact on ULUE [53]. According to the research of Zhang [2] and Gao [10], this paper selects the sum of employment in the secondary and tertiary industries to measure the labor input in each city. (4) Urbanization. The development of urbanization has created favorable conditions for economic agglomeration, and the ULUE could also increase. Meanwhile, urbanization may 
also have a negative effect on ULUE by leading to over-exploitation of urban resources and deterioration of the urban ecological environment [54]. Basing on the existing research [55], this paper uses the proportion of the population of the city district in the total population to characterize the urbanization rate. (5) Policy. Under China's economic growth-oriented performance appraisal system, local governments mainly formulate land requisition policies to expand urban land areas to alleviate problems such as insufficient local financial resources. Therefore, the policy has a significant effect on ULUE [17]. According to the study of $\mathrm{Wu}$ [16], the proportion of local fiscal expenditure to GDP is selected to quantify policy factors.

Considering the availability of data and the impact of the HSR on ULUE before the operation of HSR in 2008, the research time range of this paper is from 2005 to 2018. The HSR's operation date of each city comes from the Chinese railway timetable. Urban built-up area and socioeconomic data come from 2006 2019 China Urban Statistical Yearbook and China Urban-Rural Construction Statistical Yearbook. In order to reduce the impact of heteroscedasticity and sample dispersion, this paper takes the logarithm of the variables that measure Economic, Capital input, and Labor input. The Variables definition and descriptive statistics could be seen in Table 1.

Table 1. Variables definition and descriptive statistics.

\begin{tabular}{|c|c|c|c|c|c|}
\hline & Definition & Mean & $\begin{array}{l}\text { Standard } \\
\text { Deviation }\end{array}$ & Minimum & Maximum \\
\hline ULUE & See Equation (4) & 6.17 & 4.85 & 0.04 & 60.81 \\
\hline period & $\begin{array}{l}\text { Year After HSR operation, } 1 \\
\text { Year Before HSR operation, } 0\end{array}$ & 0.57 & 0.49 & 0 & 1 \\
\hline treated & $\begin{array}{l}\text { City has HSR, } 1 \\
\text { For no HSR, } 0\end{array}$ & 0.27 & 0.45 & 0 & 1 \\
\hline economic & per capita GDP & 10.61 & 0.71 & 8.14 & 15.68 \\
\hline capital & total investment of fixed assets & 14.82 & 1.27 & 18.81 & 5.71 \\
\hline labor & $\begin{array}{l}\text { the sum of employment in the } \\
\text { secondary and tertiary industries }\end{array}$ & 2.79 & 0.32 & 6.71 & 1.02 \\
\hline urbanization & $\begin{array}{l}\text { the proportion of the population of } \\
\text { the city district in the total } \\
\text { population }\end{array}$ & 0.35 & 0.24 & 1 & 0.21 \\
\hline policy & $\begin{array}{l}\text { the proportion of local fiscal } \\
\text { expenditure to GDP }\end{array}$ & 0.27 & 0.16 & 0.11 & 3.58 \\
\hline
\end{tabular}

\section{Results}

\subsection{Change Trends of ULUE}

Figure 3 a reflects the ULUE change trend of the whole of China and the three major regions. The ULUE and the three major regions showed a significant upward trend from 2005 to 2018. The ULUE of China's cities increased from 339 million RMB $/ \mathrm{km}^{2}$ in 2005 to 846 million $\mathrm{RMB} / \mathrm{km}^{2}$ in 2018. For the three major regions, the ULUE of Eastern China is higher than that of Central China and Western China. Specifically, the ULUE of Eastern China has increased from 509 million RMB $/ \mathrm{km}^{2}$ to 1.126 billion $\mathrm{RMB} / \mathrm{km}^{2}$, with an average annual increase of 44 million $\mathrm{RMB} / \mathrm{km}^{2}$. The ULUE of Central and Western China have similar change trends, with an average annual increase of nearly 32 million $\mathrm{RMB} / \mathrm{km}^{2}$. More interestingly, the average annual growth rate of ULUE in Central and Western China is $12 \%$ and $14 \%$, respectively, which is higher than the average annual growth rate of Eastern China. It could be indicated that the Chinese Central Government's implementation of the Central China Rise and Western China Development Strategy has promoted the development of central and western cities and improved the ULUE. 


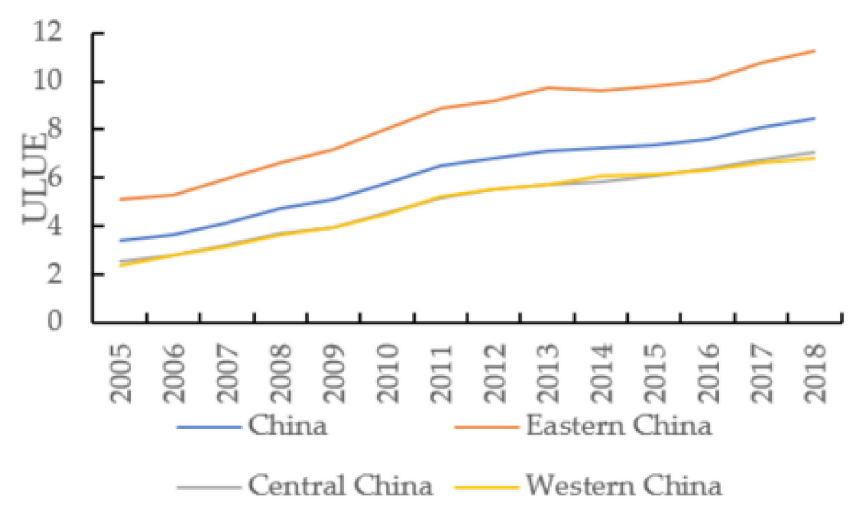

(a)

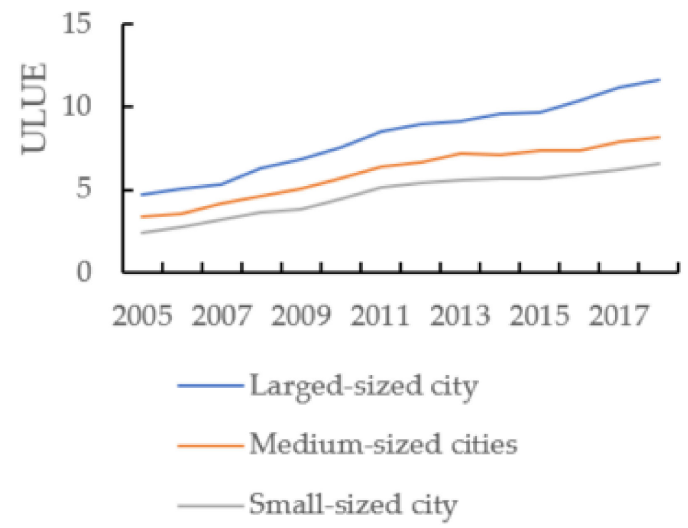

(b)

Figure 3. (a) Trends of ULUE in China and three major regions; (b) Changes in ULUE of cities for different sizes and scales.

Expect for geographic location, the level and scale of cities also lead to differences in ULUE. According to the classification method by Qi [56] et al., this paper divides Chinese cities into large-sized cities, medium-sized cities and small-sized cities. The change trend of ULUE can be seen in Figure 3b. The ULUE of large-sized cities has increased from 471 million $\mathrm{RMB} / \mathrm{km}^{2}$ in 2005 to 1.168 billion $\mathrm{RMB} / \mathrm{km}^{2}$, with an average annual increase of $50 \mathrm{RMB} / \mathrm{km}^{2}$. By comparison, the ULUE of medium-sized cities and small-sized cities is obviously lower than that of large-sized cities, with an average annual increase of 34 million $\mathrm{RMB} / \mathrm{km}^{2}$ and 30 million $\mathrm{RMB} / \mathrm{km}^{2}$ respectively. It could be indicated as such because large-sized cities have significant advantages in policy support and infrastructure construction. Therefore, large-sized cities could attract the concentration of advanced production factors and steadily improve ULUE.

\subsection{Sample Matching Results}

We used the Propensity Score Matching method to match the treated group and the untreated group and obtain the kernel density (seen in Figure 4). Before matching, the probability density distributions of the propensity score values between the treated group and the untreated group are significantly different. The data distribution of the treated group is relatively loose, and the untreated group is concentrated to the left. Figure $4 \mathrm{~b}$ reflects the kernel density distribution of propensity scores after matching. The probability density distribution of the treated group and the untreated group tends to be consistent, they both have two crests on the left and right. It could be found that, after propensity score matching, the sample selection bias is eliminated [48,49].

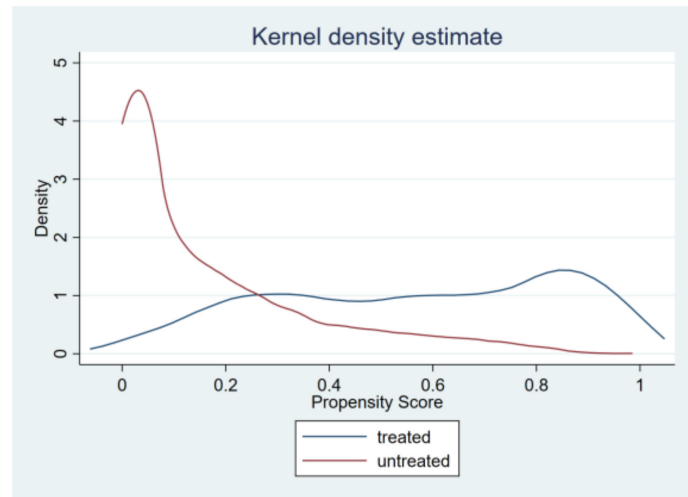

(a)

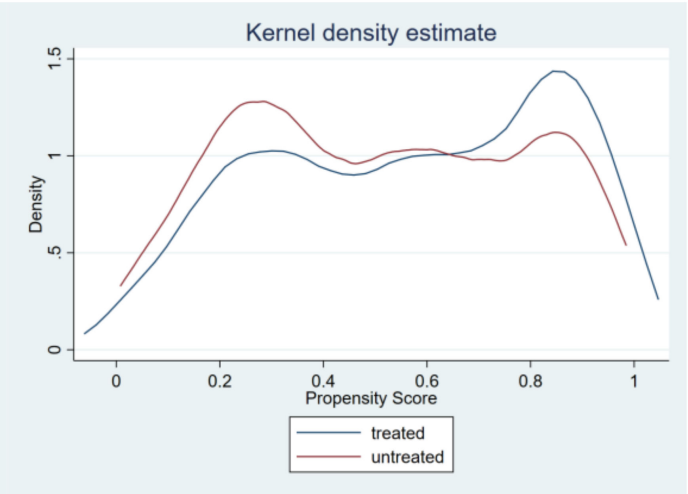

(b)

Figure 4. (a) Kernel density of Propensity Score before matching; (b) Kernel density of Propensity Score after matching. 


\subsection{Regression Results of Entire China}

In Table 2, Model 1 represents the DID regression results of 285 cities, Model 2 represents the DID results of removing cities with HSR operation after 2011, Model 3 represents the PSM-DID results of removing cities with HSR operation after 2011. The regression coefficients of the (period $\times$ treated $)_{i t}$ are $0.86,1.29$, and 1.70 , respectively, and they are all significant at the $1 \%$ level. It could be indicated that HSR has significantly improved the ULUE. Scholars have also proposed that the construction and operation of HSR have a positive effect on land expansion, air pollution control and industry agglomeration $[44,46,47]$. These are conducive to optimize the allocation of labor and capital elements, and then improve ULUE.

Table 2. Regression results of the HSR operation on ULUE.

\begin{tabular}{cccc}
\hline & Model 1 & Model 2 & Model 3 \\
\hline \multirow{2}{*}{$(\text { period } \times \text { treated })_{i t}$} & $0.86^{* * *}$ & $1.29^{* * * *}$ & $1.70^{* * *}$ \\
economic & $(0.22)$ & $(0.28$ & $(0.28)$ \\
& $2.25^{* * *}$ & $1.87^{* * *}$ & $1.211^{* * *}$ \\
capital & $(0.12)$ & $(0.14)$ & $(0.15)$ \\
& $0.62^{* * *}$ & $0.29^{* *}$ & -0.14 \\
labor & $(0.08)$ & $(0.09)$ & $(0.10)$ \\
& -0.17 & $0.37^{*}$ & $0.45^{* *}$ \\
urbanization & $(0.14)$ & $(0.15)$ & $(0.20)$ \\
& $8.96^{* * *}$ & $6.77^{* * *}$ & $\left(0.13^{* * *}\right.$ \\
policy & $(0.48)$ & $(0.58)$ & $-1.28^{* * *}$ \\
$\mathrm{R}^{2}$ & $-1.25^{* * *}$ & $-1.32^{* *}$ & $(0.29)$ \\
\hline
\end{tabular}

Note: ${ }^{*}$ represents $p$-value $<10 \%,{ }^{* *}$ represents $p$-value $<5 \%$, and ${ }^{* * *}$ represent $p$-value $<1 \%$, respectively. Standard errors in parentheses.

We further compare the results of Model 1 3. It could be found that: (1) Compared with Model 1, the (period $\times$ treated $)_{i t}$ coefficient of Model 2 increased from 0.86 to 1.29, and the model fitting value also increased from 0.46 to 0.56 . It shows that placing cities with HSR operation after 2011 into the untreated group could underestimate the effect of HSR on ULUE [6]. (2) Compared with Model 2, Model 3 based on PSM-DID has a higher regression coefficient for (period $\times$ treated $)_{i t}$, and the increase in $R^{2}$ value also shows that the model has better fit and reliability. Thereby, the following analysis will be based on the results of Model 3.

For the control variables, the level of urban economic development has a significant positive impact on ULUE. This result is consistent with the research of Yu [53]. The impact of capital input on ULUE is not significant. The main reason is that most cities in China have low technology and redundant investment in fixed assets, which causes most urban land to suffer from ineffective capital input and low output [10]. Labor input has a significant positive impact on ULUE. The increase in the number of urban labor forces promotes the formation of better job matching in cities and realizes knowledge spillover through the exchange of human capital, and improves the ULUE [2,3]. The urbanization rate has a significant positive impact on ULUE. Urbanization improves the ULUE by advancing urban infrastructure construction and improving the urban investment environment, and removing barriers to urban mobility [57]. The impact of policy factors on the ULUE is significantly negative, indicating that the economic performance competition of local governments in China has led to disorderly expansion of cities and reduced the ULUE.

\subsection{Regression Results of Regional Heterogeneity}

Previous studies demonstrated that the impact of HSR on economic growth has significant regional heterogeneity [27-29]. Therefore, on the basis of exploring the impact of HSR on ULUE at the macro level, we also should take differences caused by geographic 
location and the level and scale of cities into consideration. The regression results of PSM-DID are shown in Table 3.

Table 3. Regression results of regional heterogeneity.

\begin{tabular}{ccccccc}
\hline & \multicolumn{3}{c}{ Geographic Location } & \multicolumn{3}{c}{ Level and Scale } \\
\cline { 2 - 7 } & Model 4 & Model 5 & Model 6 & Model 7 & Model 8 & Model 9 \\
\hline \multirow{2}{*}{$(\text { period } \times \text { treated })_{i t}$} & $1.82^{* * *}$ & $1.05^{* * *}$ & 0.31 & $2.53^{* * *}$ & 0.52 & 0.54 \\
& $(0.55)$ & $(0.33)$ & $(0.75)$ & $(0.73)$ & $(0.68)$ & $(0.37)$ \\
economic & $1.57^{* * *}$ & $1.91^{* * *}$ & $0.95^{* * *}$ & $1.24^{* *}$ & $0.58^{* * *}$ & $2.10^{* * *}$ \\
& $(0.40)$ & $(0.22)$ & $(0.15)$ & $(0.60)$ & $(0.19)$ & $(0.16)$ \\
capital & -0.37 & 0.17 & -0.07 & $-1.26^{* * *}$ & $0.25^{* *}$ & -0.04 \\
& $(0.36)$ & $(0.15)$ & $(0.09)$ & $(0.48)$ & $(0.12)$ & $(0.10)$ \\
labor & -0.79 & $1.25^{* * *}$ & 0.19 & -0.61 & $1.55^{* * *}$ & $0.63^{* * *}$ \\
& $(0.48)$ & $(0.24)$ & $(0.25)$ & $(0.56)$ & $(0.34)$ & $(0.18)$ \\
urbanization & $10.08^{* * *}$ & $4.74^{* * *}$ & $4.98^{* * *}$ & $10.85^{* * *}$ & -0.97 & 0.46 \\
& $(1.26)$ & $(1.06)$ & $(1.60)$ & $(1.25)$ & $(2.011)$ & $(1.09)$ \\
policy & $-1.37^{* * *}$ & $-1.48^{* * *}$ & $-1.16^{* * *}$ & 0.02 & $-1.57^{* *}$ & $-1.11^{* * *}$ \\
$\mathrm{R}^{2}$ & $(1.27)$ & $(0.40)$ & $(0.23)$ & $(0.66)$ & $(0.68)$ & $(0.27)$ \\
& 0.57 & 0.70 & 0.67 & 0.61 & 0.67 & 0.66 \\
\hline
\end{tabular}

Note: ${ }^{*}$ represents $p$-value $<10 \%$, ${ }^{* *}$ represents $p$-value $<5 \%$, and ${ }^{* * *}$ represent $p$-value $<1 \%$, respectively. Standard errors in parentheses.

Model 4 5 represents the regression results of Eastern China, Central China, Western China, respectively. The results indicate that the operation of HSR has a significant effect on ULUE in Eastern China and Central China, while the impact of HSR on ULUE in Western China is positive, but not significant. Although the operation of HSR in Western China can significantly improve ULUE, the operation date of HSR in Western China is later than the cities in Eastern China and Central China. Meanwhile, there are fewer cities that have HSR in Western China $[38,58]$. These reasons cause the operation of HSR to have an insignificant impact on the ULUE of Western China.

Model 7 9 represents the regression results of large-sized cities, medium-sized cities and small-sized cities, respectively. It could be found that HSR has a significant positive impact on the ULUE of large-sized cities, but it is not significant for small- and mediumsized cities. The reason is that the station of HSR gives priority to setting up in large-sized cities, and the operation of HSR could further strengthen the central position of large-sized cities in the regional economy [59]. For the medium-sized cities and small-sized cities, although the operation of HSR has strengthened the economic connection between the city and regional central cities, the HSR has also led to the loss of high-quality production factors in the city [27-29]. Therefore, the impact of HSR on ULUE is not significant.

\subsection{Robustness Test}

This paper took 2011 as the implementation date of HSR, but in fact, after 2011, other cities in China have gradually opened HSR. In order to test whether the results are affected by the implementation date of HSR and improve the accuracy of the estimation, this paper attempted to use each year from 2012 to 2017 as the implementation date of HSR respectively. The results are shown in Table 4 . It can be found that, consistent with the estimated results in Table 2, after changing the implementation date of HSR, the regression coefficients of (period $\times$ treated $_{i t}$ are all significantly positive. Additionally, the regression coefficients are all greater than 1 . The result demonstrates that HSR significantly improves the urban land use efficiency level of each city. Therefore, the results of this paper have robustness. 
Table 4. The regression results of changing the implementation date of HSR.

\begin{tabular}{ccccccc}
\hline & $\mathbf{2 0 1 2}$ & $\mathbf{2 0 1 3}$ & $\mathbf{2 0 1 4}$ & $\mathbf{2 0 1 5}$ & $\mathbf{2 0 1 6}$ & $\mathbf{2 0 1 7}$ \\
\hline \multirow{2}{*}{$(\text { period } \times \text { treated })_{i t}$} & $1.18^{* * *}$ & $1.14^{* * *}$ & $1.10^{* * *}$ & $1.20^{* * *}$ & $1.29^{* * *}$ & $1.20^{* * *}$ \\
& $(0.21)$ & $(0.19)$ & $(0.18)$ & $(0.19)$ & $(0.21)$ & $(0.28)$ \\
economic & $1.18^{* * *}$ & $1.22^{* * *}$ & $1.17^{* * *}$ & $1.16^{* * *}$ & $1.18^{* * *}$ & $1.21^{* * *}$ \\
& $(0.15)$ & $(0.15)$ & $(0.15)$ & $(0.15)$ & $(0.15)$ & $(0.15)$ \\
capital & -0.15 & -0.16 & -0.15 & -0.15 & -0.15 & -0.15 \\
& $(0.10)$ & $(0.10)$ & $(0.10)$ & $(0.10)$ & $(0.10)$ & $(0.10)$ \\
labor & $0.45^{* *}$ & $0.44^{* *}$ & $0.42^{* *}$ & $0.10^{* *}$ & $0.40^{* *}$ & $0.43^{* *}$ \\
& $(0.20)$ & $(0.19)$ & $(0.20)$ & $(0.20)$ & $(0.20)$ & $(0.20)$ \\
urbanization & $8.07^{* * *}$ & $8.07^{* * *}$ & $7.99^{* * *}$ & $8.09^{* * *}$ & $8.24^{* * *}$ & $8.27^{* * *}$ \\
& $(0.74)$ & $(0.74)$ & $(0.74)$ & $(0.74)$ & $(0.74)$ & $(0.74)$ \\
policy & $-1.20^{* * *}$ & $-1.22^{* * *}$ & $-1.23^{* * *}$ & $-1.22^{* * *}$ & $-1.22^{* * *}$ & $-1.20^{* * * *}$ \\
$\mathrm{R}^{2}$ & $(0.29)$ & $(0.29)$ & $(0.29)$ & $(0.29)$ & $(0.29)$ & $(0.29)$ \\
& 0.58 & 0.58 & 0.58 & 0.58 & 0.58 & 0.58 \\
\hline
\end{tabular}

Note: ${ }^{*}$ represents $p$-value $<10 \%,{ }^{* *}$ represents $p$-value $<5 \%$, and ${ }^{* * *}$ represent $p$-value $<1 \%$, respectively. Standard errors in parentheses.

In Table 2, we control the covariates that affect the opening probability of HSR in each city through the Propensity Score Matching method. However, since we do not fully consider other covariates that may affect the operation of HSR and ULUE, we cannot completely summarize the results of this paper as the impact of the operation of HSR. According to the method of Zhang [60], we treat cities with HSR service after 2011 as the treated group, and use the PSM-DID method for counterfactual testing. If the regression result of the counterfactual test is contrary to Model 3, it means that the results of this paper are reasonable. The counterfactual test results are shown in Table 5. The results show that the regression coefficient of the (period $\times$ treated) ${ }_{i t}$ is significantly negative, while the results of Model 3 are significantly positive. The counterfactual test once again demonstrates that the results of this paper are robust.

Table 5. The result of counterfactual test.

\begin{tabular}{cc}
\hline & Counterfactual Test \\
\hline$(\text { period } \times \text { treated })_{i t}$ & -1.70 \\
Control variables & $(0.28)$ \\
$\mathrm{R}^{2}$ & Yes \\
\hline
\end{tabular}

Note: ${ }^{*}$ represents $p$-value $<10 \%$, ${ }^{* *}$ represents $p$-value $<5 \%$, and ${ }^{* * *}$ represent $p$-value $<1 \%$, respectively. Standard errors in parentheses.

\section{Discussion}

The construction and operation of high-speed rail has become an important measure of the Chinese government to promote efficiency and fairness and high-quality economic growth. Previous studies have examined the effect of HSR on China's economic growth and verified the existence of the HSR's economic effect [24-26]. Meanwhile, while construction and operation of HSR promote the flow of production factors such as labor and capital, HSR and its stations could occupy land and cause changes in urban land use structure. Thereby, the construction and operation of HSR may become one of the effective policies to improve the ULUE. However, few studies have explored the impact of high-speed rail on ULUE. This paper constructs the theoretical framework and proposes that HSR affects ULUE by promoting the flow of labor and capital elements, changing the land use structure and land use value. Then, we constructed the Propensity Score Matching-Differences in Differences model to evaluate the effect of HSR on ULUE. From both theoretical and empirical aspects, this paper enriches the research between HSR and urban land use. 
Our results demonstrated that the construction and operation of HSR promotes the growth of ULUE. For cities, the construction and operation of HSR creates perfect conditions for land use and development. However, it should be noted that the construction of highspeed railway should be consistent with the urban land use planning. Combined with the needs of urban development, the government should reasonably determine the type and scale of land around HSR stations. The land around the HSR station should be dominated by the high-speed railway service function, and focus on meeting the commercial service land and storage demand for the improvement of passenger flow and freight flow brought by the operation of HSR. When the government plans and constructs the residential land around the HSR station, it needs to support and construct the educational, medical and transportation infrastructure needed by the residential land, so as to avoid low land use efficiency caused by lack of urban infrastructure.

Meanwhile, we also found that, due to the difference of urban different geographic location and urban scale, the impact of high-speed rail on land use efficiency is heterogeneous. These results emphasize the Chinese government's need to pay attention to the differences of the impact of high-speed rail, and then formulate differentiated HSR construction planning and urban development planning. For cities in Eastern and Central China and large-sized cities, it is necessary to pay attention not only to the advantages of regional centrality improvement brought by HSR, but also to the negative problems of urbanization that may be caused by HSR. Western China and small- and medium-sized cities should rely on the operation of HSR and their own specialized industries, build a business core area and logistics transportation center with HSR stations. Meanwhile, Western China and small- and medium-sized cities also need to promote the flow of factors with nearby cities that have not yet opened HSR, so as to complement each other's advantages and improve urban land use efficiency.

However, there are several limitations in this study, which could be improved in future studies. For example, this paper does not study the specific path of HSR to improve the ULUE. Meanwhile, this paper does not construct a spatial econometric model to explore the spatial spillover effects of HSR on ULUE. Due to the network characteristics of HSR, most of the studies proposed that the impact of high-speed rail on urban economic development and land use is not only limited to the city, but also to the surrounding cities $[5,59]$. Therefore, analyzing the specific impact mechanism of the construction and operation of HSR on ULUE and exploring the spatial spillover effects of HSR on ULUE are the research direction that can be concerned in the future.

\section{Conclusions}

On the basis of previous studies, this paper constructed a Propensity Score MatchingDifferences in Differences model to explore the impact of HSR on ULUE. The results of the whole of China demonstrate that the construction and operation of HSR could significantly improve the ULUE. Meanwhile, this paper also considered the heterogeneity of results caused by differences in urban geographic location and urban scale. It demonstrates that HSR has a significantly positive effect on ULUE of Eastern and Central China and large-sized cities, but the impact on ULUE of Western China, medium-sized cities and small-sized cities in China is not significant. Thereby, the government should pay attention to the service role of HSR in formulating urban development planning and urban land use planning, so as to realize the unity of high-speed railway construction and operation and urban development.

Author Contributions: Supervision; funding acquisition; writing-review and editing, X.L.; conceptualization; software; methodology; writing — original draft and editing, Y.T.; data curation; visualization; resources. S.K. All authors have read and agreed to the published version of the manuscript.

Funding: This study was supported by the National Natural Science Foundation of China (Nos. 41801205), China Postdoctoral Science Foundation Project (Nos. 2020M672365) and National 985 Project of Non-traditional Security at Huazhong University of Science and Technology. 
Conflicts of Interest: The authors declare no conflict of interest.

\section{References}

1. Zitti, M.; Ferrara, C.; Perini, L.; Carlucci, M.; Salvati, L. Long-Term Urban Growth and Land Use Efficiency in Southern Europe: Implications for Sustainable Land Management. Sustainability 2015, 7, 3359. [CrossRef]

2. Zhang, W.; Zou, J.; Wu, Q. Effect of production factors on urban land use efficiency: Based on the provincial data of different development stages. Resour. Sci. 2020, 42, 1416-1427. [CrossRef]

3. Li, Y.; Shu, B.; Wu, Q. Urban Land Use Efficency in China: Spatial and Temporal Characteristics, Regional Difference and Influence Factors. Econ. Geogr. 2014, 34, 133-139.

4. Du, J.; Thill, J.; Peiser, R.B. Land pricing and its impact on land use efficiency in post-land-reform China: A case study of Beijing Cities 2016, 50, 68-74. [CrossRef]

5. Wang, L.; Li, H.; Shi, C. Urban land-use efficiency, spatial spillover, and determinants in China. Acta Geogr. Sin. 2015, 70, 1788-1799.

6. Dong, Y.; Zhu, Y. Can High-Speed Rail Construction Reshape the Layout of China's Economic Space-Based on the Perspective of Regional Heterogeneity of Employment, Wage and Economic Growth. China Ind. Econ. 2016, 10, 92-108.

7. Liu, S.; Xiao, W.; Li, L.; Ye, Y.; Song, X. Urban land use efficiency and improvement potential in China: A stochastic frontier analysis. Land Use Policy 2020, 99, 105046. [CrossRef]

8. Dong, Y.; Jin, G.; Deng, X. Dynamic interactive effects of urban land-use efficiency, industrial transformation, and carbon emissions. J. Clean. Prod. 2020, 270, 122547. [CrossRef]

9. Zhu, X.; Li, Y.; Zhang, P.; Wei, Y.; Zheng, X.; Xie, L. Temporal-spatial characteristics of urban land use efficiency of China's $35 \mathrm{mega}$ cities based on DEA: Decomposing technology and scale efficiency. Land Use Policy 2019, 88, 104083. [CrossRef]

10. Gao, X.; Zhang, A.; Sun, Z. How regional economic integration influence on urban land use efficiency? A case study of Wuhan metropolitan area, China. Land Use Policy 2020, 90, 104329. [CrossRef]

11. Lu, X.; Kuang, B.; Li, J. Regional difference decomposition and policy implications of China's urban land use efficiency under the environmental restriction. Habitat Int. 2018, 77, 32-39. [CrossRef]

12. Tone, K. A slacks-based measure of efficiency in data envelopment analysis. Eur. J. Oper. Res. 2001, 130, 498-509. [CrossRef]

13. Kuang, B.; Lu, X.; Zhou, M.; Chen, D. Provincial cultivated land use efficiency in China: Empirical analysis based on the SBM-DEA model with carbon emissions considered. Technol. Forecast. Soc. Chang. 2020, 151, 119874. [CrossRef]

14. Yang, B.; Chen, X.; Wang, Z.; Li, W.; Zhang, C.; Yao, X. Analyzing land use structure efficiency with carbon emissions: A case study in the Middle Reaches of the Yangtze River, China. J. Clean. Prod. 2020, 274, 123076. [CrossRef]

15. Chen, W.; Ning, S.; Chen, W.; Liu, E.; Wang, Y.; Zhao, M. Spatial-temporal characteristics of industrial land green efficiency in China: Evidence from prefecture-level cities. Ecol. Indic. 2020, 113, 106256. [CrossRef]

16. Wu, C.; Wei, Y.D.; Huang, X.; Chen, B. Economic transition, spatial development and urban land use efficiency in the Yangtze River Delta, China. Habitat Int. 2017, 63, 67-78. [CrossRef]

17. Tu, F.; Yu, X.; Ruan, J. Industrial land use efficiency under government intervention: Evidence from Hangzhou, China. Habitat Int. 2014, 43, 1-10. [CrossRef]

18. Sun, Y.; Ma, A.; Su, H.; Su, S.; Chen, F.; Wang, W.; Weng, M. Does the establishment of development zones really improve industrial land use efficiency? Implications for China's high-quality development policy. Land Use Policy 2020, 90 , 104265. [CrossRef]

19. Chen, W.; Shen, Y.; Wang, Y.; Wu, Q. The effect of industrial relocation on industrial land use efficiency in China: A spatial econometrics approach. J. Clean. Prod. 2018, 205, 525-535. [CrossRef]

20. Han, W.; Zhang, Y.; Cai, J.; Ma, E. Does Urban Industrial Agglomeration Lead to the Improvement of Land Use Efficiency in China? An Empirical Study from a Spatial Perspective. Sustainability 2019, 11, 986. [CrossRef]

21. Cui, X.; Fang, C.; Wang, Z.; Bao, C. Spatial relationship of high-speed transportation construction and land-use efficiency and its mechanism: Case study of Shandong Peninsula urban agglomeration. J. Geogr. Sci. 2019, 29, 549-562. [CrossRef]

22. Yang, T.; Guan, X.; Qian, Y.; Xing, W.; Wu, H. Efficiency Evaluation of Urban Road Transport and Land Use in Hunan Province of China Based on Hybrid Data Envelopment Analysis (DEA) Models. Sustainability 2019, 11, 3826. [CrossRef]

23. Givoni, M. Development and Impact of the Modern High-speed Train: A Review. Transp. Rev. 2007, 26, 593-611. [CrossRef]

24. Blum, U.; Haynes, K.E.; Karlsson, C. Introduction to the special issue the regional and urban effects of high-speed trains. Ann. Reg. Sci. 1997, 31, 1-20. [CrossRef]

25. Wetwitoo, J.; Kato, H. High-speed rail and regional economic productivity through agglomeration and network externality: A case study of inter-regional transportation in Japan. Case Stud. Transp. Policy 2017, 5, 549-559. [CrossRef]

26. Chen, Z.; Haynes, K.E. Impact of high-speed rail on regional economic disparity in China. J. Transp. Geogr. 2017, 65, 80-91. [CrossRef]

27. Jia, S.; Zhou, C.; Qin, C. No difference in effect of high-speed rail on regional economic growth based on match effect perspective? Transp. Res. Part A Policy Pract. 2017, 106, 144-157. [CrossRef]

28. Diao, M. Does growth follow the rail? The potential impact of high-speed rail on the economic geography of China. Transp. Res. Part A Policy Pract. 2018, 113, 279-290. [CrossRef] 
29. Hiramatsu, T. Job and population location choices and economic scale as effects of high speed rail: Simulation analysis of Shinkansen in Kyushu, Japan. Res. Transp. Econ. 2018, 72, 15-26. [CrossRef]

30. Wang, C.; Chen, N.; Chan, S. A gravity model integrating high-speed rail and seismic-hazard mitigation through land-use planning: Application to California development. Habitat Int. 2017, 62, 51-61. [CrossRef]

31. Chen, Z.; Zhou, Y.; Haynes, K.E. Change in land use structure in urban China: Does the development of high-speed rail make a difference. Land Use Policy 2020, 104962. [CrossRef]

32. Zhang, G.; Zheng, D.; Wu, H.; Wang, J.; Li, S. Assessing the role of high-speed rail in shaping the spatial patterns of urban and rural development: A case of the Middle Reaches of the Yangtze River, China. Sci. Total Environ. 2020, 704, 135399. [CrossRef]

33. Huang, Z.; Du, X. How does high-speed rail affect land value? Evidence from China. Land Use Policy 2020, 101, 105068. [CrossRef]

34. Lu, D. Bravely take on the historical mission of strengthening the railway with strong transportation and strive to open up a new era for China's railway reform and development. China Railw. 2019, 1, 1-8.

35. Cui, X.; Wang, X. Urban land use change and its effect on social metabolism: An empirical study in Shanghai. Habitat Int. 2015, 49, 251-259. [CrossRef]

36. Guirao, B.; Campa, J.L.; Casado-Sanz, N. Labour mobility between cities and metropolitan integration: The role of high speed rail commuting in Spain. Cities 2018, 78, 140-154. [CrossRef]

37. Garmendia, M.; de Ureña, J.M.; Ribalaygua, C.; Leal, J.; Coronado, J.M. Urban Residential Development in Isolated Small Cities That Are Partially Integrated in Metropolitan Areas by High Speed Train. Eur. Urban Reg. Stud. 2008, 15, 249-264. [CrossRef]

38. Yu, Y.; Pan, Y. Does High-speed Rail Reduce the Rural-urban Income Disparity? An Interpretation Based on the Perspective of Heterogeneous Labor Mobility. China Rural Econ. 2019, 37, 79-95.

39. Wang, F.; Wei, X.; Liu, J.; He, L.; Gao, M. Impact of high-speed rail on population mobility and urbanisation: A case study on Yangtze River Delta urban agglomeration, China. Transp. Res. Part A Policy Pract. 2019, 127, 99-114. [CrossRef]

40. Duan, L.; Sun, W.; Zheng, S. Transportation network and venture capital mobility: An analysis of air travel and high-speed rail in China. J. Transp. Geogr. 2020, 88, 102852. [CrossRef]

41. Lu, X.; Ke, S. Evaluating the effectiveness of sustainable urban land use in China from the perspective of sustainable urbanization. Habitat Int. 2018, 77, 90-98. [CrossRef]

42. Nuworsoo, C.; Deakin, E. Transforming High-speed Rail Stations to Major Activity Hubs: Lessons for California. In Proceedings of the 88th Annual Meeting of the Transportation Research Board, Washington, DC, USA, 11-15 January 2009.

43. Shaw, S.; Fang, Z.; Lu, S.; Tao, R. Impacts of high speed rail on railroad network accessibility in China. J. Transp. Geogr. 2014, 40, 112-122. [CrossRef]

44. Deng, T.; Wang, D.; Yang, Y.; Yang, H. Shrinking cities in growing China: Did high speed rail further aggravate urban shrinkage? Cities 2019, 86, 210-219. [CrossRef]

45. Ashenfelter, O. Estimating the Effect of Training Programs on Earnings. Rev. Econ. Stat. 1978, 60, 47-57. [CrossRef]

46. Yang, X.; Lin, S.; Li, Y.; He, M. Can high-speed rail reduce environmental pollution? Evidence from China. J. Clean. Prod. 2019, 239, 118135. [CrossRef]

47. Shao, S.; Tian, Z.; Yang, L. High speed rail and urban service industry agglomeration: Evidence from China's Yangtze River Delta region. J. Transp. Geogr. 2017, 64, 174-183. [CrossRef]

48. Heckman, J.J. The common structure of statistical models of truncation, sample selection and limited dependent variables and a simple estimator for such models. Ann. Econ. Soc. Meas. 1976, 5, 475-492.

49. Rosenbaum, P.R.; Rubin, D.B. The central role of the propensity score in observational studies for causal effects. Biometrika 1983, 70, 41-55. [CrossRef]

50. He, S.; Yu, S.; Li, G.; Zhang, J. Exploring the influence of urban form on land-use efficiency from a spatiotemporal heterogeneity perspective: Evidence from 336 Chinese cities. Land Use Policy 2020, 95, 104576. [CrossRef]

51. Lu, M. Cross regional reallocation of construction land use right: The new driving force of China's economic growth. J. World Econ. 2011, 34, 107-125.

52. Yu, J.; Zhou, K.; Yang, S. Land use efficiency and influencing factors of urban agglomerations in China. Land Use Policy 2019, 88 , 104143. [CrossRef]

53. Gu, N.; Chen, X. Fiscal constraints, urban expansion and economic agglomeration density, labor productivity changes. Economist 2015, 30-40. [CrossRef]

54. Bai, Y.; Deng, X.; Jiang, S.; Zhang, Q.; Wang, Z. Exploring the relationship between urbanization and urban eco-efficiency: Evidence from prefecture-level cities in China. J. Clean. Prod. 2018, 195, 1487-1496. [CrossRef]

55. Liu, S.; Ye, Y.M.; Xiao, W. Spatial-Temporal Differentiation of Urban Land-Use Efficiency in China Based on Stochastic Frontier Analysis. China Land Sci. 2020, 34, 61-69.

56. Qi, W.; Liu, S.; Jin, H. Applicability of the new standard of city-size classification in China. Prog. Geogr. 2016, 35, 47-56.

57. Turok, I.; McGranahan, G. Urbanization and economic growth: The arguments and evidence for Africa and Asia. Environ. Urban 2013, 25, 465-482. [CrossRef] 
58. Wang, K.; Xia, W.; Zhang, A. Should China further expand its high-speed rail network? Consider the low-cost carrier factor. Transp. Res. Part A Policy Pract. 2017, 100, 105-120. [CrossRef]

59. Wang, J.; Jiao, J.; Jin, F. Spatial effects of high-speed rails on interurban economic linkages in China. Acta Geogr. Sin. 2014, 69, 1833-1846.

60. Zhang, J. High-speed rail construction and county economic development: The research of satellite light data. China Econ. $Q$. 2017, 16, 1533-1562. 